\title{
Granuloma telangiectásico en cavidad oral
}

\section{Telangiecticum granuloma in oral cavity}

\author{
Rebolledo Cobos $\mathrm{M}^{*}$, Harris Ricardo J**, Cantillo Pallares O***, \\ Carbonell Muñoz Z****, Díaz Caballero A*****
}

\section{RESUMEN}

El granuloma telangiectásico es un tumor de origen epitelial benigno que tiene predilección en cavidad oral a nivel de la encía, de contenido vascular y de crecimiento rápido, cuya etiología es atribuible a irritantes locales como placa bacteriana, calculo, traumatismos, presencia de restos radiculares y otros como la presencia de cuerpos extraños. Esta patología es muy semejante a granuloma periférico de células gigantes, hemangioma capilar, carcinoma epidermoide exofítico, sarcoma de Kaposi, nevos pigmentados, melanomas, fibroma periférico y otros tumores mesenquimatosos. A continuación se presenta caso clínico de una paciente femenina de 71 años de edad quien acude al servicio de Estomatología y Cirugía Oral de la facultad de odontología de la Universidad de Cartagena por presentar una lesión tumoral en maxilar inferior que sangraba con facilidad el cual abarcaba una extensión desde órgano dental 34 a órgano dental 43. Se procedió a realizar la escisión quirúrgica de la lesión tumoral y se envió a patología donde se confirmó diagnostico de granuloma telangiectásico.

Palabras clave: Granuloma telangiectásico, tumor benigno epitelial, escisión quirúrgica.

\section{SUMMARY}

The telangiecticum granuloma is a benign tumor of epithelial origin with preference for oral cavity, specially at the gum. It is rich in vascular content and rapid growth. It's aetiology is attributable to local irritants such as bacterial plaque, dental calculus, trauma, and presence of root, others such as the presence of foreign bodies. This pathology is very similar to the peripheral giant cell granuloma, capillary hemangioma, exophytic squamous cell carcinoma, Kaposi's sarcoma, snowy pigmented melanomas, peripheral fibroma and mesenchymal tumors. In present paper is showed a clinical case of a female 71 years old who goes to the service of Stomatology and Oral Surgery at the School of Dentistry, University of Cartagena for presenting a tumor in jaw that was bleeding easily covering a body length from teeth number 34 to teeth number 43 . We proceeded to perform surgical excision of the tumor and sent to pathology where it was confirmed diagnosis of telangiecticum granuloma.

Key words: Granuloma telangiecticum, benign neoplasm, oral surgical procedures.

Fecha de recepción: 5 de junio de 2009.

Aceptado para publicación: 20 de junio de 2009.

* Odontóloga, Residente de Estomatología y Cirugía Oral Universidad de Cartagena.

** Odontólogo. Residente de Estomatología y Cirugía Oral, Universidad de Cartagena.

*** Odontólogo. Universidad de Cartagena. Profesor titular Universidad de Cartagena.

**** Estomatólogo y Cirujano Oral universidad de Cartagena, Profesor titular Universidad de Cartagena.

***** Odontólogo. Universidad de Cartagena. Profesor titular Universidad de Cartagena.

Rebolledo Cobos M, Harris Ricardo J, Cantillo Pallares O, Carbonell Muñoz Z, Díaz Caballero A. Granuloma telangiectásico en cavidad oral. Av. Odontoestomatol 2010; 26 (5): 249-253. 


\section{INTRODUCCIÓN}

El Granuloma telangiectásico es un tumor que anteriormente se denominaba Granuloma Piógeno del embarazo o gravídico que se presenta en la mucosa gingival durante el embarazo o asociado con el uso de anticonceptivos orales por las cargas hormonales que se presentan en estas condiciones (1). También es llamado épulis cuya etiología era atribuible a microorganismos como Estafilococos o Estreptococos. En la actualidad se define como una lesión benigna de la mucosa gingival a consecuencia de un trauma e irritación local como por ejemplo exfoliación de dientes primarios, espículas óseas, trauma del cepillado, irritación gingival por placa y cálculo sobre todo cuando están localizados en encía $(2,3)$.

El trauma e irritación constante de cualquiera de estos factores produce una ulceración que debido a la irritación no sana y se forma tejido de granulación abundante en el intento de recuperación, por esto se produce la lesión (4). Aparentemente las infecciones pulpares también pueden provocar respuestas proliferativas de los tejidos como se presenta en esta lesión tumoral.

Las hormonas y otros factores pueden modificar la respuesta y promover el desenvolvimiento de tejido hiperplásico o de granulación, el cambio hormonal tanto del embarazo como de la pubertad modifican el curso clínico de esta entidad patológica (5), ya que los niveles de estrógeno y progesterona son marcadamente incrementados en estas etapas y pareciera que ejercen un efecto proliferativo hacia el endotelio en el granuloma telangiectásico (6), además existen informes de que la progesterona tiene un impacto importante en el sistema vascular gingival, al incrementar el fluido gingival lo cual afecta la integridad de las células del endotelio capilar (7).

En un estudio realizado por Ono et al en el 2002 se reporta que el granuloma telangiectásico se encuentra en el $5 \%$ de las lesiones benignas en cavidad oral, en un rango de edad de 40-50 años, en proporción 1:1 hombre y mujeres, con 19 semanas de aparición de los síntomas y el sitio más frecuente de aparición fue la lengua (8). Al-khateeb y Ababneh en el período de 1991 a 2001 determinaron que el rango de edad de los pacientes comprendía entre 3-85 años, con el más alto grado de incidencia $(26,8 \%)$ en la segunda década de vida. La proporción de varón a hembra era $1: 1,7$. El sitio más frecuentemente fue la encía $(44,4 \%)$. La queja principal fue el sangrado $(59,3 \%)$

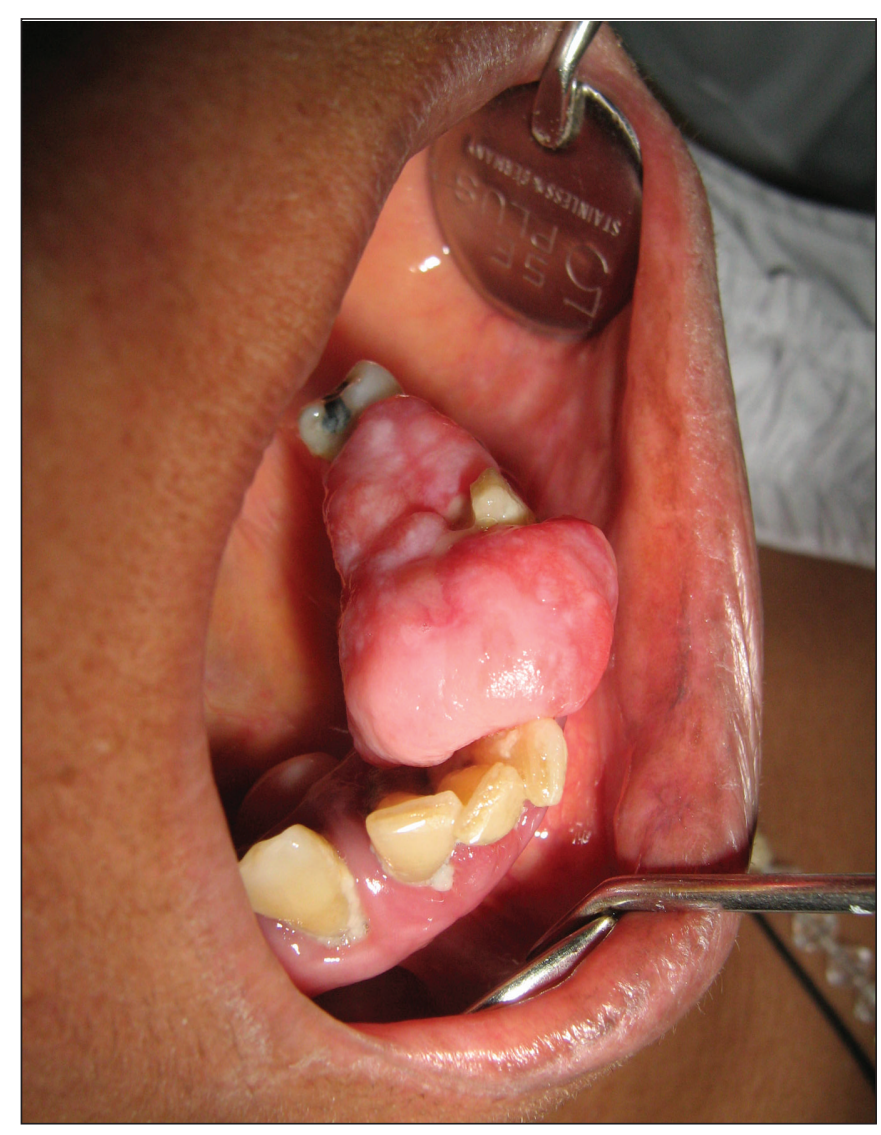

Fig. 1. Foto clínica intraoral de granuloma telangiectásico.

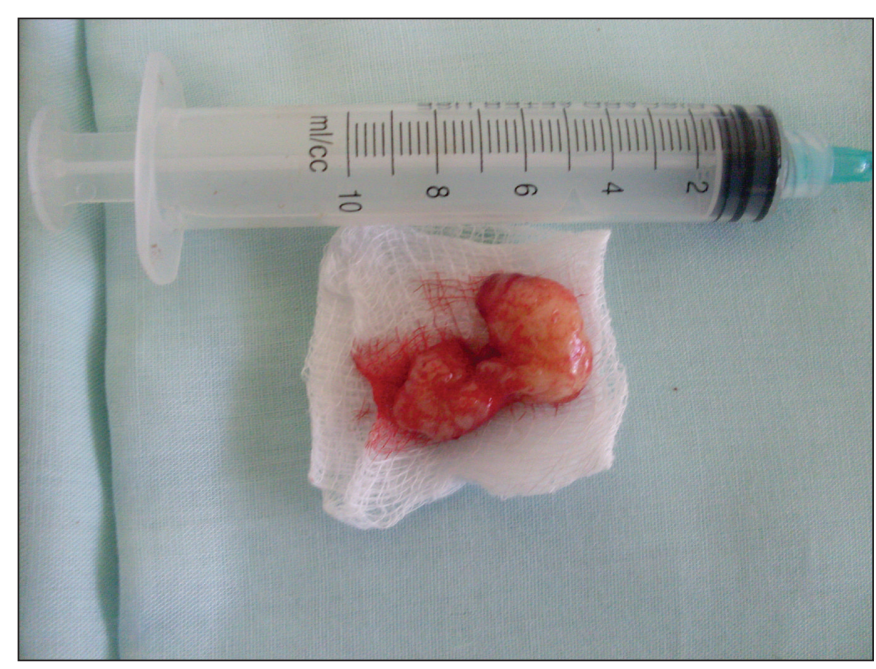

Fig. 2. Imagen microscópica posquirúrgica de granuloma telangiectásico. 
y casi la mitad de las lesiones tenía base pediculada, con la ulceración de la superficie en 9,2\% de casos (9). Aldape, Padilla y Cruz en el 2006 encontraron que el número de registros de estudios histopatológicos diagnosticados en el laboratorio de patología bucal en el periodo de enero de 1997 a diciembre de 2001 fue de 3.293 correspondiendo el granuloma telangiectásico con 150 casos (4,2\%) (10).

\section{CARACTERÍSTICAS CLÍNICAS}

El Granuloma telangiectásico, por lo general es exofítico puede ser pediculado o sésil y de consistencia blanda, la superficie puede ser lisa, granular o lobulada debido a los espacios vasculares superficiales dilatados que producen una apariencia de mora (11). Puede encontrarse ulcerada dependiendo de su localización y la exposición a irritación traumática, o puede estar necrótica y cubierta por un fluido blanco que clínicamente semeja pus. Tienen tendencias a hemorragias cuando son manipulados (12). El color va en un rango entre rosa pálido y rojo vino tinto, si ha ocurrido hemorragia en la lesión esta se torna marrón. En cuanto al tamaño pueden ir desde milímetros hasta varios centímetros de hecho pueden alcanzar grandes tamaños en corto tiempo.

Las lesiones jóvenes son suaves en su textura, las más antiguas son firmes y parecen fibromas. Cuando están ulceradas dan la errónea apariencia de una lesión maligna y más aun si esto se combina con su potencial para destruir hueso subyacente (13).

Diagnósticos diferenciales:

- Granuloma periférico de células gigantes.

- Hemangioma capilar.

- Carcinoma metastásico

- Sarcoma de Kaposi

- Fibroma periférico.

- Melanoma cuando es hemorrágico (13).

En cuanto al tratamiento se debe realizar la eliminación quirúrgica de la lesión, la cual debe incluir la eliminación del tejido conectivo del cual surge la patología, así como cualquier factor etiológico local como cálculo o placa dental $(14,15)$. La eliminación quirúrgica también se puede realizar por crio- cirugía y cirugía láser, que pueden resultar unas buenas alternativas en aquellos casos en los cuales se quiera un mejor control del sangrado pero existen pocos reportes de los resultados de este tratamiento (16). La recurrencia se puede observar en ocasiones y se cree, que puede deberse a la eliminación incompleta o una falla al eliminar los factores etiológicos (14).

\section{CASO CLÍNICO}

Paciente femenina de 71 años de edad que acude al servicio de Estomatología y Cirugía Oral de una Universidad en Cartagena, Colombia, por presentar lesión en la mandíbula. La paciente refiere que hace 5 años presenta lesión tumoral a nivel mandibular, que aumenta paulatinamente de tamaño con el pasar del tiempo, manifestando sangrado espontáneo, asintomático, dificultaba la articulación de las palabras y la masticación; entre los antecedentes personales reporta Hipertensión Arterial controlada con Metoprolol de $50 \mathrm{mg}$ diario, no presenta otras alteraciones considerables en otros órganos y sistemas. Al examen intraoral se observó una lesión tumoral multilobulada en maxilar inferior que se extiende desde órgano dental 34 a órgano dental 43 por encía adherida vestibular y lingual, de $4,5 \mathrm{~cm}$ de diámetro, móvil, de consistencia blanda, pediculado, de color rojo intenso, con áreas fibrosas de color amarillo, sangrante a la palpación y asintomático; se evidenció alrededor de la lesión abundante placa bacteriana, cálculo y restos radiculares correspondiente a los órganos dentales 33, 34, 35 que, a su vez, presentaron movilidad grado III (avanzada). Se realizaron los estudios paraclínicos pertinentes como radiografía panorámica y oclusal los cuales demostraron desplazamiento de los órganos dentales implicados y perdida ósea avanzada. Se ordenaron exámenes de laboratorio como hemograma completo y pruebas de coagulación como TP y TPT cuyos resultados se encontraron dentro de los parámetros normales.

\section{Procedimiento}

Previo a la firma de un consentimiento informado donde se explicaron a la paciente las posibles compli- 
caciones y técnicas de sepsia y antisepsia se procede a la realización de la escisión quirúrgica de la lesión tumoral, realizando bloqueo anestésico mediante las técnicas anestésicas mandibulares bilaterales con lidocaína al 2\% con epinefrina al 1:80.000. Se realizan exodoncias de los órganos dentales implicados 31, 32, 33, 34, 35, 41, 42, 43, 44, 45 y órgano dental 46 , posteriormente se realiza la aprehensión de la lesión tumoral con pinzas alix, para incidir sobre la base del pedículo con hoja de bisturí \#15 para mango Bard Parker \#3 y de esta forma obtener la lesión tumoral para incluirlo en formol al $10 \%$, seguidamente se realiza curetaje profundo del lecho quirúrgico con cureta de Luckas, regularización de crestas óseas interceptales con pinza gubia, hemostasia e irrigación del área quirúrgica con suero fisiológico y finalmente la síntesis del procedimiento quirúrgico realizando afrontamiento de los bordes incididos con Vicryl 3-0.

Se indican recomendaciones posoperatorias y se establece terapia medicamentosa antibiótica, con Amoxicilina cápsulas de 500 mg \#21, por vía oral cada 8 horas durante 7 días, y analgésica antiinflamatoria con Nimesulide 100 mg \#6 tabletas por vía oral cada inflamado 12 horas por 3 días. Se cita para control a los ocho días subsecuentes al procedimiento donde se observo buen proceso de cicatrización, ausencia de exudados purulentos o sintomatología dolorosa.

El reporte patológico muestra una lesión constituida por una proliferación fibrocolágena y altamente vascularizada con un infiltrado inflamatorio crónico y áreas ulceradas. No se observó malignidad ni atipias celulares en la muestra examinada, correspondiente a un granuloma telangiectásico.

\section{DISCUSIÓN}

El granuloma telangiectásico es considerado como una lesión reactiva vascular benigna que afecta que afecta algunos tejidos blandos de la cavidad oral como encía, mucosas labiales, lengua y rebordes alveolares, a consecuencia de un trauma e irritación local como exfoliación de dientes primarios, espículas óseas recidivantes, trauma del cepillado, irritación gingival por placa y cálculo sobre todo cuando están localizados en encía $(1,2)$ coincidiendo con los datos clínicos acerca de la etiología del caso presentado, por la presencia de placa bacteriana y calculo acompañado de una deficiente higiene oral que corresponden a los factores etiológicos de esta lesión tumoral.

En un estudio realizado por Al-khateeb y Ababneh en el período de 1991 a 2001 determinaron que el rango de edad de los pacientes comprendía entre 3-85 años, con el más alto grado de incidencia (26.8\%) en la segunda década de vida. En cuanto al sexo, en este mismo estudio se reporta una proporción de varón a hembra de $1: 1,7$. coincidiendo con este caso, que presenta una paciente del género femenino cuya edad es de 71 años. El sitio más frecuentemente fue la encía $(44,4 \%)$ coexistiendo esta frecuencia con este reporte. La queja principal fue el sangrado $(59,3 \%)$ y casi la mitad de las lesiones tenía base pediculada, con la ulceración de la superficie en $9.2 \%$ de casos (8) en concordancia con este caso que presentó zonas hemorrágicas y pediculado.

Otros estudios referentes a las características clínicas manifiestan que el granuloma telangiectásico, por lo general es elevado, puede ser pediculado o sésil y generalmente de consistencia blanda. La superficie puede ser lisa, granular o lobulada debido a los espacios vasculares superficiales dilatados que producen una apariencia de mora. El color va en un rango entre rosa pálido y rojo vino tinto, si ha ocurrido hemorragia en la lesión esta se torna marrón. La superficie puede encontrarse ulcerada dependiendo de su localización y la exposición a irritación traumática, la superficie puede estar necrótica y cubierta por un fluido blanco que clínicamente semeja pus. Tienen tendencias a hemorragias cuando son manipuladas $(10,11)$, en coincidencia con el caso las estas manifestaciones clínicas reportadas son semejantes al caso reportado.

En cuanto al tratamiento se debe realizar la eliminación quirúrgica de la lesión la cual debe incluir la eliminación del tejido conectivo del cual surge la patología, así como cualquier factor etiológico local como cálculo o placa dental (12), como se realizó en el caso presentado. 


\section{BIBLIOGRAFÍA}

1. Bork K, Hoede N et al. Diseases of the oral mucosa and the lips. 2a ed. Philadelphia: Saunders 1996:229-31.

2. Elmustafa OM, Badie AA. Lingual granuloma gravidarum. Saudi Med J 2001 Dec;22(12): 1130-2.

3. Lee J, Lynde C. Pyogenic granuloma: pyogenic again? Association between pyogenic granuloma and Bartonella. J Cutan Med Surg. 2001 NovDec;5(6):467-70.

4. Sánchez JG, Villarroel M, López-Labady J, Mata de Henning M. Granuloma piogénico. Reporte de dos casos de aparición inusual y revisión de la literatura Act Odont Vzlna 1999;38(2):36-40.

5. Yuan K, Wing LY, Lin MT. Pathogenetic roles of angiogenic factors in pyogenic granulomas in pregnancy are modulated by female sex hormones. J Periodontol 2002 Jul;73(7):701-8.

6. Whitaker SB, Bouquot JE, Alimario AE, Whitaker TJ Jr. Identification and semiquantification of estrogen and progesterone receptors in pyogenic granulomas of pregnancy. Oral Surg Oral Med Oral Pathol 1994 Dec;78(6):755-60.

7. Mohamed AH, Waterhouse JP, Fredereci HH. The microvasculature of the rabbit gingival as affected by progesterone: an untrastructural study. J Periodontol 1974;45:69.

8. Ono Y, Takahashi H, Inagi K, Nakayama M, Okamoto M. Clinical study of benign lesions in the oral cavity. Acta Otolaryngol. Suppl, 2002; (547):79-84.
9. Al-khateebt T, Ababneh K. Oral Pyogenic Granuloma in Jordanians: A Retrospective Analysis of 108 Cases. J Oral Maxillofac Surg 2003;(61): 1285-8.

10. Aldape B, Padilla G, Cruz B. Frecuencia de lesiones bucales histopatológicas en un laboratorio de patología bucal. Revista ADM 2007;LXIV(2):61-67.

11. Aguilo L. Pyogenic granuloma subsequent to injury of a primary tooth. A case report International. J Paediatr Dent 2002;(12):438-41.

12. Garcia I y cols. Hemangioma lobular capilar (granuloma piógeno) asociado a la erupción: Reporte de dos casos clínicos. Revista Odontológica Mexicana 2004 Diciembre; 8(4):127-32.

13. Meffert JJ, Cagna DR, Meffert RM. Treatment of oral granulation tissue with the flashlamp pulsed dye laser. Dermatol Surg 1998 Aug;24(8): 845-8.

14. Vieira T y cols. Estudo epidemiológico de lesões proliferativas não neoplásicas da mucosa oral análise de 20 anos. Rev Cienc Odontol Bras 2002; 5(3):55-60.

15. Duarte E y cols. Investigación retrospectiva de granulomas telangiectásicos. Universidad Nacional del Nordeste. J Dev Comm 2006:1-2.

16. Powell J, Bailey C, Coopland A, Otis C, Frank J, Meyer I. Nd:YAG laser excision of giant gingival granuloma of pregnancy. Laser Surg Med 1994; 14:178-83.

\section{CORRESPONDENCIA}

Martha Rebolledo Cobos

malereco18@hotmail.com 